\title{
"You're opening yourself up to new and different ideas": Clinical psychologists' understandings and experiences of using reflective practice in clinical work: an interpretative phenomenological analysis.
}

Word Count: 6220 (including Abstract, Main Body, Tables and References)

\begin{abstract}
Reflective practice is an essential competency in clinical psychology training and practice. However, evidence is limited to support the role of reflection in clinical practice. This study investigated the lived experiences of clinical psychologists' use of reflective practice in the context of their clinical work. Seven clinical psychologists completed reflective diaries and semi-structured interviews to facilitate in-depth reflections on clinical events. Interview transcripts were analyzed using interpretative phenomenological analysis.

Three superordinate themes and six subthemes were developed from the data: Exploratory Questioning (gaining a different perspective, new insight and opening new possibilities), Containment of own Thoughts and Feelings in Practice, and Human Survival (managing the emotional impact, self-sustaining and leaving work at work). Consideration of these findings suggested that reflective practice plays a key role in clinical psychologists' perspective-taking abilities; allowing them to maintain an open and curious clinical perspective. Reflective practice enables containment, which impacts the building and maintaining of therapeutic relationships. Reflective practice relieves discomfort and promotes personal resilience. Further research on clinician use of reflective practice can contribute to understanding this core competency which is highly relevant to the training and ongoing development of clinical psychologists.
\end{abstract}

Keywords: reflective practice, interpretative phenomenological analysis, qualitative research methods, diary, clinical psychology, self-care 
Reflective practice has been defined as “... a mode that integrates or links thought and action with reflection. It involves thinking about and critically analyzing one's actions with the goal of improving one's professional practice" (Imel, 1992, p. 2). Within clinical psychology, selfawareness and learning from experience have been referred to as two broader meanings of reflective practice (Stedmon, Mitchell, Johnstone \& Staite, 2003). Schön's (1983) influential work on reflective practice describes two types of reflection: reflection-on-action and reflection-in-action which should both enable the practitioner to make more informed and useful decisions in the future.

The literature on reflective practice has emphasized the important role it plays in managing the complexity and uniqueness of clinical work, where the limitations of relying solely on technical knowledge have been highlighted (Schön, 1983; Stedmon \& Dallos, 2009). It is highly valued across health professions (Gale \& Schröder, 2014; Mann, Gordon \& MacLeod, 2009; Knight, Sperlinger \& Maltby, 2010). In clinical psychology, both the Health and Care Professions Council (HCPC) and the British Psychological Society (BPS) recognize reflection as a core clinical competency (BPS, 2017; HCPC, 2015) and have integrated the reflective-practitioner model into clinical psychology training programmes alongside the scientist-practitioner model.

There is some research to support the benefits of reflective practice on clinical psychologists' personal and professional development (PPD), including improving selfawareness (XXXX, XXXX \& XXXX, 2015) and enhancing the connection with the client (Binks, Jones \& Knight, 2013). The wider literature suggests reflection enables learning from experience, and is most often used in novel or challenging situations (Mann et al., 2009).

A key assumption underlying the literature is that clinical practice would benefit from integrating reflective practice alongside the scientist-practitioner model. However, there is a limited evidence and theory base for reflective practice in the area of clinical practice to 
support this assertion. Most of the research has focused on the benefits of reflective practice on PPD and has been carried out on trainees who are still developing this skill (e.g. BennettLevy et al., 2001; Wigg, Cushway \& Neal, 2011) and who have likely been influenced by the group setting (i.e. reflective practice groups), which many training programmes use to develop reflective competences (Gillmer \& Marckus, 2003). Research that has attempted to address this gap has tended to explore the role of reflective practice more generally as opposed to reflective practice specifically linked to clinical practice (e.g. XXXX et al., 2015).

One of the main difficulties encountered in the literature is with defining and describing reflective practice (XXXX et al., 2015; Paula, 2003). Research methods that have been used to explore reflective practice have tended to rely on observational methods (Mann et al., 2009) or retrospective interviews alone, which have limitations in terms of being able to access clinicians' knowledge of their reflections, especially in capturing more moment-tomoment reflections (Burgess, Rhodes and Wilson, 2013) and different levels of reflection such as reflection-in-action and reflection-on-action.

Given that there is little understanding within clinical psychology on the use of reflective practice, and previous research has not fully captured clinicians' actual experiences, the present study will use Interpretative Phenomenological Analysis (IPA: Smith \& Osborn, 2003) to understand the lived experience of clinical psychologists' use of reflective practice. IPA's idiographic focus allows for a detailed and in-depth understanding of an individual's experience, which it is hoped will move the research on from general perspectives of reflective practice to specific experiences grounded in clinical work that capture different levels of reflection. This could contribute to guidance on how reflective practice is represented in the training of clinical psychologists and as an ongoing competence. The study aims to address the following question: "What are clinical psychologists' experiences of using reflective practice in their clinical work?" 


\section{Materials and Methods}

\section{Design}

The study used the qualitative approach of IPA to produce an account of the participants' own personal lived experience of reflective practice. The study was committed to a phenomenological epistemology (Smith, Jarman \& Osborn, 1999), which is concerned with exploring individuals' subjective experience rather than defining an objective reality (Reid, Flowers \& Larkin, 2005). The method is idiographic due to its emphasis on a detailed and indepth examination of each individual (Smith, Flowers \& Larkin, 2009).

\section{Participants}

Inclusion criteria were used to recruit qualified clinical psychologists who self-identified as reflective and valued the use of reflection. This group was considered more likely to provide meaningful data regarding potential uses of reflective practice in clinical practice. Inclusion criteria were:

- Qualified clinical psychologist

- Fluent in written and spoken English

- Interested in and value reflective practice

- Use reflective practice in clinical work

- Currently working in a clinical setting

Given that the study was committed to carrying out a detailed analysis of each individual experience a small sample was recruited to generate rich and meaningful data. A purposive sample of seven participants (four females) were recruited by advertising the study through the Research and Development team from different clinical services within the National Health Service (NHS) (see Table 1 for details). Pseudonyms were chosen by the participants to preserve anonymity. 
Clinical psychologists use of reflective practice

Table 1 about here

\section{Procedure}

The study involved two stages; the first involved participants completing a demographic questionnaire and recording diary reflections on specific clinical events over a three-week period; the second involved participants attending a one-hour semi-structured interview. The diary was brought in to the interview to help participants reflect further on their previous reflections. An interview schedule, developed through a pilot interview, was used to prompt discussion around relevant topics such as: the participants' understanding of reflective practice; participants' use of reflective practice in their clinical work and more specifically how they used their diary reflections, which was the main focus of the interview.

Interviews were transcribed verbatim. The diaries were not coded in the IPA analysis as this data was included in the interview by participants reflecting on specific reflections from their diary.

\section{Data Collection}

Demographic questionnaire. This enquired about participants' clinical role and level of reflection, and was designed to provide some context to the participants' clinical reflections as well as to help ensure participants were self-identifying as reflective practitioners.

Reflective diary. The diary was a tool to help participants record their reflections as close as possible to when they occurred, with the aim being to capture participants' reflections as close to the experience as possible and to help facilitate a focus in the interview on specific events in clinical practice. Participants were encouraged to use their preferred method for recording their reflections, in order to help them reflect in a way that felt natural and useful for them. The diary was brought into the interview to help facilitate further in-depth reflection on 
clinical events. Participants were prompted by the researcher to choose two reflections from their diary to further reflect on.

Semi-structured interview. The interview aimed to explore participants' reflections on their experience of reflective practice in the context of their clinical work; the diary was used to facilitate. Interviews were prepared in accordance with the recommendations of Smith et al. (2009) and were conducted by the first author. This involved establishing rapport, providing guidance on what was expected and emphasising that the research was not concerned with producing an objective account. The interview guide was shared with the participants and was explained as a road map in which there was flexibility based on their account (Smith \& Osborn, 2003).

\section{Ethical issues}

Ethical approval was obtained from the University of East Anglia Ethics Committee and the Health Research Authority (HRA) granted approval to carry out the research in NHS organizations in England. All participants provided signed consent prior to taking part in the study.

\section{Analysis}

IPA was used to perform a line-by-line analysis of the transcripts, using six stages of analysis as a guide (Smith et al., 2009). Following an iterative and inductive process (Smith, 2007), each individual transcript was coded with initial thoughts, which were used to develop emergent themes. These themes were then condensed by placing them into conceptual clusters to produce higher-order themes, which conveyed the conceptual nature of the themes. Smith et al's. (2009) metaphor of imagining some themes as magnets pulling other themes towards 
them, was useful for this part of the analysis. Once this process was completed for each participant, a cross-case analysis was performed to identify commonalities across the participants' accounts, in which superordinate themes were developed.

\section{Quality and Validity}

Yardley's (2000) four principles were applied to ensure quality and validity appropriate to IPA. These were: sensitivity to context; commitment and rigour; transparency and coherence; and impact and importance. IPA is an interpretative activity; therefore a reflexive position was taken throughout to acknowledge and to some degree manage the influence of the researcher's pre-understandings (Smith et al., 2009).

\section{Results}

The analysis produced three superordinate themes: Exploratory Questioning, Containment of own Thoughts and Feelings in Practice and Human Survival. Table 2 provides the representation of the themes across the participants.

Table two about here

\section{Exploratory questioning}

The first superordinate theme contained three themes: gaining a different perspective, new insight and opening new possibilities. This theme, which was present across all participants, captures the process of how they were using reflection, the outcome of their reflecting and how they generally experienced reflection. All seven participants described a process of questioning that helped them to access or discover a new meaning, and for some participants this led to an opportunity to make progress in their clinical work.

\subsection{Gaining a different perspective.}


Reflection was experienced as a way of accessing a different perspective. For some participants this represented either their curiosity about how others perceive things, their own uncertainty or a need to make sense of a feeling. One participant reflected on different layers of reflection and described these as representing different perspectives:

And then later on in the day I might think...about it from their perspective or question my own stance and whether that related to something about how I see the world, and my background. And then I might go home and talk to somebody, um, about that and get their view on it and that would be sort of another layer. (Joe)

Reflecting on reflections in the interview helped guide participants in taking a new perspective, which helped change how they felt about that particular situation.

...it helped me to gain perspective on the situation about how I've ended up in a rather passive position, which I didn't probably want to be in. Um, I think it probably helped me understand better, some of his smaller interactions...And I think I was also able to use it to...I suppose feel less, perhaps a bit less guilty, uh, a bit less blamed for, kind of it was an unhelpful situation for him. (Monica)

In contrast to these attempts at analyzing one's thoughts and feelings, Sally's experience of reflection focused on being able to distance herself from thoughts and feelings; this helped her see things in a different way.

Reflection helps you to distance yourself from, get some psychological distance so you can observe it and be, and try and be a bit more objective about things a bit. So I found that useful. (Sally) 


\subsection{New insight.}

This theme was closely related to gaining a different perspective but captured a deeper level of understanding, either of the participants themselves, others or an experience. Participants were thinking back over an experience using their diaries to record this and then further reflecting on this experience in the interview. This process allowed the participants to gain new insight into their own thoughts and feelings and their clinical work:

I was there with no goodbye, erm, I was like, "Oh God, yeah, poor boy," like, "This is not about you, Lucy, or him not wanting to say goodbye to you or him being rude or him not appreciating what, the work that you guys have just done or him not having enjoyed that or you being a bad practitioner. (Lucy)

For Lucy, reflecting on her initial feelings ('annoyed' and 'rejected') after a final session with a client helped her to make sense of her reaction, enabling her to access a more empathic understanding of the client's behavior. Lucy's experience of reflecting led to a powerful change from feeling 'angry', due to interpreting an external event as though it was directly related to her, to feeling 'sad' after understanding the function of the client's behavior. Similarly for Sally reflection helped her gain new insight into her clinical work:

And through my reflection, I'm able to stand back, um, kind of and try and understand the motivations. And what... what's not working. What isn't working. And it's- and it's helping me to empathize more. (Sally)

\subsection{Opening new possibilities.}

Participants experienced reflection as leading to more opportunities and possibilities by being comfortable with uncertainty, slowing clinical work down and being more aware of 
themselves and their client. Participants experienced 'doubt' (Vicky) and 'being unsure' (John) as valuable opportunities to pay attention to things they may not have noticed if they had rushed ahead with a more certain view.

I suppose reflection is about again that slowing, pausing, questioning, doubting, wondering, and in that process, you're opening yourself up to new and different ideas and, and attending to things that maybe would have been missed. (Vicky)

John experienced reflection as 'sitting with a lot of unknowns', which seemed related to his belief that you can 'never fully know yourself' or be certain about your understanding of others. This helped him notice meaningful changes in his clients.

By observing, by sort of sitting with those unknowns, observing those things, first my behavior and then, kind of, getting a best guess about how I was feeling and maybe what was going on we, we, sort of, did manage to get to somewhere in the session that was more meaningful and that he was engaging with...(John)

Bryan experienced reflection as a way of giving him more choice by being more aware of his thoughts and feelings. This awareness enabled him to decide on his response to his feelings, as opposed to reacting without realizing.

I guess it helped me kind of name what I was feeling... and why I was like, you know...But then it also made me think...could I have said it in a different way, it might have been a bit less threatening... and I suppose that kind of thing. So it's helpful to kind of take that step back to think. (Bryan)

\section{Containment of own Thoughts and Feelings in Practice}


The second superordinate theme encapsulated reflection as a way of containing the participants' own thoughts and feelings in their practice. In contrast to the other two themes, this superordinate theme did not contain any subthemes. This reflected the strength and significance of containment to the participants' experience and as such this theme could be made sense of without supporting subthemes. Reflection appeared to be used to help participants feel more able to focus on their clients' needs by being more able to understand and manage their own. Lucy provides an example of this experience:

It was consensual, "What, what does consent mean?” And me having gone away and thought about that, and, I think then helped him to be able to reflect, because I was, kind of, prepared and ready for it myself. I suppose, I had contained my thoughts and feelings around it. (Lucy)

Lucy reflected on a previous session with a client when in the moment she was unsure about how to respond to a client's concern. Identifying and making sense of her own thoughts and feelings about the client's concern helped Lucy feel more contained and ready to help the client make sense of this for himself. This was a similar experience for Monica where reflection on feeling 'stuck' with a client resulted in a more containing experience for her and her client.

I think she would've probably experienced me as...hopefully a little bit more containing, isn't it? Uh, um, yeah. In the same way that we talked earlier about coming in and appearing more contained, I suppose, a more consistent attachment object for them, for the client...And therefore we're able to perhaps, experience her own emotions. (Monica) 
Bryan shared a similar experience of reflecting when something felt 'tricky' with a client and then using reflection to become more aware of his thoughts and feelings enabling him to be less reactive in his approach.

... like making those things unconscious, more conscious....just helping you be aware of what's...going on and what's happening and...how your feeling and what's...what the possible reasons around that. Coz I guess, once your... aware of something then its... you can, it gives you that choice or it helps you to...to decide. (Bryan)

In contrast to this experience of containment through exploring and making sense of one's own thoughts, Sally's experience of feeling 'grounded', was facilitated more through distancing herself from her thoughts:

Trying to literally kinda ground myself in-in a kind of like, "Right, okay." You know, sort of trying to not get caught up in my, maybe, thinkings. Or, um, if I'm feeling maybe a bit on edge or defensive...trying to kind of bring that down... Or just...trying to be aware of my surroundings and just kind of just be in the moment. (Sally)

Sally's experience of reflection appeared to be influenced by her recent interest in Acceptance and Commitment Therapy (ACT). Sally's reference to the 'observer self' may explain her use of reflection in helping her stand back from her thoughts rather than analyzing them.

\section{Human Survival}

The third superordinate theme contained three themes: managing the emotional impact of work, self-sustaining and leaving work at work. Human survival was constructed from the 
participants' descriptions of using reflection as a form of self-care and resilience. In contrast to Containment of own Thoughts and Feelings in Practice, this theme developed from the participants taking care of themselves as opposed to focusing directly on the clients' needs.

\subsection{Managing the emotional impact.}

This theme developed from the participants expressing difficult and painful emotions triggered by their work, which reflection helped them manage. Joe provides an example of how participants described using reflection for their own self-care needs and not just for their clients' therapeutic needs:

I think our work produces a lot of discomfort, a lot of difficult feelings. And so, the better you can feel, um, the better you're gonna work. But yeah, I guess a lot of reflection is - is for me, as well, to feel more comfortable with what I'm doing. (Joe)

This was also powerfully demonstrated by Bryan's reference to his own experience of personal therapy, which he described as a form of reflection:

so yeah....thinking where you are in that coz as I say I...go to have therapy... which is just being able to talk about those things and reflect about that kind of stuff, which I really value. (Bryan)

Lucy demonstrates this theme of survival by emphasizing the negative impact of not reflecting. She described how being able to understand empathetically the function of a client's behavior through reflection was a containing process for her.

So, if you're not able to reflect upon that and to know that there's a reason why you're doing it, there's a reason behind their behavior...How does that link to the formulation? What is that like for me? God, I think, I think you'd be on the ground. I think you, there's only so much you can take. (Lucy) 
In contrast to the other participants who emphasized the value of reflecting in this theme, Sally highlighted the potential consequence of over-reflecting which could be experienced as overwhelming rather than as a containing process:

Hmm. Yeah, if I were to kind of keep going over what, gosh, what it must be like and for people in really terrible situations, you know. Um. Then that can be, that can be really hard. I think there's a balance, I think, um, that might then make my work too emotionally involved... (Sally)

\subsection{Self-sustaining.}

Some participants' experiences of reflective practice appeared to be used as a way of enabling them to continue working in a way that was satisfying. This was a powerful theme within John's account where his repeated use of 'sustainable' suggested the importance he placed on his reflective practice in helping him feel competent.

I think being able to reflect on when things are going positively and recognizing that... and appreciating that makes it more sustainable...I think whether it's positive or negative. So, like, when - in this case, when it was positive, it's good for self-care for my ability to carry on doing the work, erm have confidence in myself (John)

Within Monica's account, reflecting on her reflections helped her recognize that she had done the best she could, given 'the human being' that she is. She was able to access compassion towards herself from this deeper level of reflection. She responded to what it would be like to have not reflected on a difficult case:

...well I wouldn't have left my job but certainly my immediate reaction was, "I can't do this anymore" ...mm, if I hadn't reflected, it's a good question... what would have 
been different? I think I would feel a lot less keen to try and work with clients with interpersonal difficulties. Um, and I think that the tendency to go actually I'm just, this isn't for me. (Monica)

Joe contributed to this theme with the language he used in his reflections to describe how he manages feelings of hopelessness and also how these help him to feel less stuck and more positive:

I guess I feel like that was helpful for me, at the time, to write something down and then...it's out there I guess...it was some kind of externalizing of it rather than carrying it around, and you've kind of put it somewhere. Um, so you just process something in sort of a different way. Um, and then...some solutions or resolutions will follow, naturally, from doing that. (Joe)

\subsection{Leaving work at work.}

Four of the participants' accounts contributed to this theme on the influence of reflection on their home life. Lucy's example powerfully captured this theme:

So, if I can contain it for myself then I am then able to go into the world and be a normal person, that doesn't come home and, you know, project onto my family. (Lucy)

Joe's use of reflection served a similar function to Lucy's, which he described as 'not wanting to take too many difficult emotions home'. Joe displayed how he tries to make sense of his negative feelings by asking himself questions (i.e. 'Why is that?' 'Is that helpful', 'What can I do with that emotion?') when he feels troubled. He found this to be a useful process in helping him let go of these troubled feelings so they didn't impact on his home life. 
Yeah, so I guess one benefit, for me, of reflecting when it - when it feels sort of useful or when it feels like...I haven't got somewhere or... when I feel like I've done some useful reflecting, um, it would help me to leave work at work. (Joe)

Vicky's experience of reflection was being influenced by her current relationship with work, which she was finding challenging, and therefore potentially explains why her account of reflection felt more negative in its focus on avoiding reflection on work outside of work, due to not wanting to 'mentally carry work' with her.

Um, and I think also my relationship with work, at the moment, is quite challenging um, so that's the wider system that we were talking, certainly has an impact on how much outside of work you wanna mentally carry work with you. (Vicky)

\section{Discussion}

This study aimed to gain an in-depth understanding of how clinical psychologists use reflective practice in their clinical work by exploring their lived experience of reflective practice. An IPA approach produced three superordinate themes that captured participants' experiences of discovery through their questioning, containment through making sense of their thoughts and feelings, and finally their survival in the clinical psychologist role.

Questioning and making sense of one's own thoughts and feelings were key ways that participants engaged in reflective practice. Critically examining the origins of their assumptions allowed room for other perspectives and interpretations. The findings suggest that these reflective processes can help manage the influence of biases, create awareness of more possibilities and influence clinical judgement. These reflective processes closely align with clinical psychologists' perspective-taking abilities, which are necessary for good clinical decision making as well as building and maintaining relationships (DCP, 2010). The 
important role of reflective practice in clinical decision making is recognised by the BPS in their good practice guidelines (BPS, 2017).

Reflective practice helped participants make sense of difficult and unique experiences, which often led to the discovery of a new meaning or avenue to explore in their clinical work. This experience of reflection appears to guide participants through uncertainty or 'stuckness' (XXXX et al., 2015), which resonates with Schön's $(1983,1987)$ idea that the process of reflection provides direction within situations of uncertainty, uniqueness and conflict. Participants' experiences of reflection showed an openness to uncertainty and a willingness to question and challenge one's own assumptions. Being open to uncertainty, which is viewed as inherent to engaging in reflective practice (Bolton, 2010; Heneghan, Wright \& Watson, 2014), enabled participants to access and consider different perspectives, which is considered good professional practice for clinical psychologists (BPS, 2017).

Reflective practice was used as a form of containment for the participants, which helped them feel more able to attend to and manage their clients' needs. This experience of containment could be an important focus for development of competency in non-specific therapist factors such as the working alliance with clients, which reflection has been found to enhance (XXXX et al., 2015; Gale \& Schröder, 2014). The ability to contain one's self in order to contain the client seems particularly important for clinical psychologists, considering their role in reducing psychological distress and enhancing and promoting psychological wellbeing (BPS, 2017). These skills are also important for the development of clinical psychologists' wider responsibilities in leadership, such as supervision and consultation (DCP, 2010).

This study highlighted the importance of reflection in participants' own self-care by helping them manage the longer-term impact of their clinical work. This normalizing use of reflection in looking after oneself makes sense considering participants' reflections led to 
containment and discovery, both of which are regarded as important components of delivering psychological therapy to help others (Padesky, 1993; Roth, Hill \& Pilling, 2009). These findings suggest that reflective practice was helpful to participants as it relieved discomfort and promoted personal resilience.

The role of reflection in enhancing self-care and therefore the personal resilience of clinical psychologists has received little attention in either research or teaching to trainee clinical psychologists. There is growing recognition of the impact of burnout and stress of healthcare staff and the relationship between staff wellbeing and patient outcomes is strong (Hall, Johnson, Watt, Tsipa \& O’Connor, 2016); given this there is an increasing need to improve staff wellbeing. Further research would benefit from exploring the role of reflective practice in protecting clinical psychologists, and other healthcare staff, from emotional exhaustion as this is not only important for them as individuals, but also for the quality of care they provide.

Overall, the themes of how reflection was used in clinical practice overlap and appear to represent a cyclical process of exploring, discovering, and containing, with surviving as an outcome of both discovery and containment. This idea that the processes involved in reflective practice are unlikely to be linear and do not occur in isolation is consistent with previous research (Wigg, Cushway \& Neal, 2011). Many different models of reflection exist in the literature with most describing reflection as learning from experience (Gibbs, 1988; Kolb, 1984). Although the study is consistent with this idea, the findings also highlight other processes in the cycle of reflection, which are more related to self-care and personal resilience.

\section{Strengths, Limitations and Future Directions}


The study was committed to the theoretical underpinnings of IPA and therefore provides an in-depth analysis of a small group of participants. Due to the interpretative nature of IPA, it is possible to construct many different useful meanings from the participants' experiences.

This research has potential implications for how we support clinical psychologists' perspective-taking abilities as this is not only an important skill in the direct work (e.g. assessment and therapy) of a clinical psychologist but also the indirect work (e.g. consultancy and leadership) which is becoming more central to the role (BPS, 2017). Furthermore, the findings suggest we should also be seeking to understand reflective practice in the context of personal resilience, as current models of reflection have only captured the role of reflection in learning, skill development and changing practice. It seems important to consider the variety of ways in which reflection is being used in different contexts and how this is contributing to the development and maintenance of competency and resilience in clinical psychologists.

The study was unique in its methodology of using reflective diaries to facilitate reflection on specific clinical events in qualified clinical psychologists. Diaries have been a common method in health and social research (Jones, 2000; Smith, 1999) yet the combined use of diaries and interviewing is less established. The diary method for capturing specific inthe-moment reflections helped provide a focus on clinical events as well as providing opportunities for deeper levels of reflection however it is acknowledged that the textual data contained in the diaries was not subject to analysis and this would be a useful next step in the literature".

The study has started to address a key criticism of the research literature by understanding how reflective practice is being used in clinical practice as opposed to reporting clinicians' general views of reflective practice (Burgess et al, 2013). The research supports the value of both reflection-in-action and reflection-on-action in clinical psychology. Exploring reflection that is grounded in clinical practice may help in developing a more 
Clinical psychologists use of reflective practice

coherent understanding of reflective practice and its applications.

Funding Details: Nothing to declare

Disclosure of interest: The authors report no conflict of interest.

Data availability statement: The qualitative data pertaining to this research is held by the University of East Anglia. 
References

Binks, C., Jones, F. W., \& Knight, K. (2013). Facilitating reflective practice groups in clinical psychology training: A phenomenological study. Reflective Practice, 14(3), 305-318. https://doi.org/10.1080/14623943.2013.767228

Bennett-Levy, J., Turner, F., Beaty, T., Smith, M., Paterson, B., \& Farmer, S. (2001). The value of self-practice of cognitive therapy techniques and self-reflection in the training of cognitive therapists. Behavioral and Cognitive Psychotherapy, 29(2), 203-220. https://doi.org/10.1017/S1352465801002077

Bolton, G. (2010). Reflective practice: Writing and professional development. London: Sage Publications.

British Psychological Society (BPS). (2015). Standards for the accreditation of Doctoral programmes in clinical psychology. Leicester: British Psychological Society.

British Psychological Society (BPS). (2017). Practice Guidelines (3rd ed.) Leicester: British Psychological Society.

Burgess, S., Rhodes, P., \& Wilson, V. (2013). Exploring the in-session reflective capacity of clinical psychology trainees: An interpersonal process recall study. Clinical Psychologist, 17(3), 122-130. doi:10.1111/cp.12014

Division of Clinical Psychology (2010). Clinical psychology leadership development framework. Leicester, UK: British Psychological Society.

\section{XXXX (2015). XXXXXXXXXX}

Gale, C., \& Schröder, T. (2014). Experiences of self-practice/self-reflection in cognitive behavioral therapy: A meta-synthesis of qualitative studies. Psychology and 
Clinical psychologists use of reflective practice

Psychotherapy: Theory, Research and Practice, 87(4), 373-392.

doi:10.1111/papt.12026

Gibbs, G. (1988). Learning by Doing: A guide to teaching and learning methods. Oxford: Oxford Polytechnic Further Education Unit Oxford.

Gillmer, B., \& Marckus, R. (2003). Personal professional development in clinical psychology training: Surveying reflective practice. Clinical Psychology, 27, 20-23.

Hall, L. H., Johnson, J., Watt, I., Tsipa, A. \& O’Connor, D. B. (2016). Healthcare staff wellbeing, burnout, and patient safety: A Systematic review. PLoSONE11(7):e0159015.doi:10.1371/journal. pone.0159015

Health and Care Professions Council (2015). Standards of proficiency: Practitioner psychologists. London: HCPC.

Heneghan, C., Wright, J., \& Watson, G. (2014). Clinical psychologists' experiences of reflective staff groups in inpatient psychiatric settings: a mixed methods study. Clinical Psychology \& Psychotherapy, 21(4), 324-340. doi:10.1002/cpp.1834

Imel, S. (1992). Reflective practice in adult education. ERIC Digest No. 122.

Jones, R. K. (2000). The unsolicited diary as a qualitative research tool for advanced research capacity in the field of health and illness. Qualitative Health Research, 10(4), 555-567. https://doi.org/10.1177/104973200129118543

Knight, K., Sperlinger, D., \& Maltby, M. (2010). Exploring the personal and professional impact of reflective practice groups: A survey of 18 cohorts from a UK clinical psychology training. Clinical Psychology and Psychotherapy, 17, 427-437. doi:10.1002/cpp.660 
Clinical psychologists use of reflective practice

Kolb, D. A. (1984). Experimental learning: Experience as the source of learning and development. Enlewood Cliffs, NJ: Prentice Hall.

Mann, K., Gordon, J., \& MacLeod, A. (2009). Reflection and reflective practice in health professions education: A systematic review. Advances in Health and Science Education, 14, 595-621. https://doi.org/10.1007/s10459-007-9090-2

Padesky, C. A. (1993, September). Socratic questioning: Changing minds or guiding discovery. In A keynote address delivered at the European Congress of Behavioral and Cognitive Therapies, London (Vol. 24).

Paula, C. (2003). Bubbles in a pond. Reflections in clinical practice. Clinical Psychology, 27, 27-29.

Reid, K., Flowers, P., \& Larkin, M. (2005). Exploring lived experience. The Psychologist, 18(1), 20-23. Link: https://goo. gl/9ScDxi.

Roth, A., Hill, A., \& Pilling, S. (2009). The competences required to deliver effective Humanistic Psychological Therapies. London: University College London.

Schön, D. F. (1983). The reflective practitioner. New York: Basic Books.

Schön, D. A. (1987). Educating the reflective practitioner: Toward a new design for teaching and learning in the professions. San Francisco: Jossey Bass.

Smith, B. A. (1999). Ethical and methodologic benefits of using a reflexive journal in hermeneutic-phenomenologic research. Journal of Nursing Scholarship, 31(4), 359363. doi:10.1111/j.1547-5069.1999.tb00520.x 
Clinical psychologists use of reflective practice

Smith, J. A. (2007). Hermeneutics, human sciences and health: Linking theory and practice. International Journal of Qualitative Studies on health and Well-being, 2(1), 311. https://doi.org/10.1080/17482620601016120

Smith, J.A., Flowers, P., \& Larkin, M. (2009). Interpretative phenomenological analysis: Theory, method and research. London: Sage Publications.

Smith, J. A., Jarman, M., \& Osborn, M. (1999). Doing interpretative phenomenological analysis. In Murray, M., \& Chamberlain, K. (Eds.). (1999). Qualitative health psychology: Theories and methods (pp. 218-240). London: Sage Publications.

Smith, J.A., \& Osborn, M. (2003). Interpretive phenomenological analysis. In J.A. Smith (Ed.) Qualitative Psychology: A practical guide to research methods (pp.51-80). London: Sage Publications.

Stedmon, J., \& Dallos, R. (2009). Reflections on reflections. In J. Stedmon \& R. Dallos (Eds.), Reflective practice in psychotherapy and counselling (pp. 176-198). Berkshire: McGraw-Hill Education.

Stedmon, J., Mitchell, A., Johnstone, L., \& Staite, S. (2003). Making reflective practice real: problems and solutions in the South West. Clinical Psychology, 27(7), 30-33.

Wigg, R., Cushway, D., \& Neal, A. (2011). Personal therapy for therapists and trainees: a theory of reflective practice from a review of the literature. Reflective Practice, 12(3), 347-359. https://doi.org/10.1080/14623943.2011.571866

Yardley, L. (2000). Dilemmas in qualitative health research. Psychology and health, 15(2), 215-228. https://doi.org/10.1080/08870440008400302 
Clinical psychologists use of reflective practice

Table 1. Participant characteristics

\begin{tabular}{|c|c|c|c|c|c|}
\hline $\begin{array}{l}\text { Pseudo- } \\
\text { nyms }\end{array}$ & $\begin{array}{l}\text { Age } \\
\text { group }\end{array}$ & $\begin{array}{l}\text { Years since } \\
\text { qualified }\end{array}$ & $\begin{array}{l}\text { Client } \\
\text { group }\end{array}$ & Type of service & $\begin{array}{l}\% \text { of Time } \\
\text { spent on } \\
\text { direct } \\
\text { clinical } \\
\text { work }\end{array}$ \\
\hline Bryan & $35-44$ & 5 - 10 years & $\begin{array}{l}\text { Adults / } \\
\text { older adults }\end{array}$ & $\begin{array}{l}\text { Adult Mental } \\
\text { Health }\end{array}$ & $50-65 \%$ \\
\hline Sally & $25-34$ & Last 2 years & $\begin{array}{l}\text { Children } \\
\text { and } \\
\text { families }\end{array}$ & $\begin{array}{l}\text { Paediatric } \\
\text { Psychology }\end{array}$ & Above $85 \%$ \\
\hline John & $25-34$ & $2-5$ years & Adults & Forensic inpatient & $50-65 \%$ \\
\hline Lucy & $25-34$ & $2-5$ years & Children & $\begin{array}{l}\text { Child and } \\
\text { Adolescent Mental } \\
\text { Health Service }\end{array}$ & $30-45 \%$ \\
\hline Joe & $25-34$ & Last 2 years & $\begin{array}{l}\text { Looked } \\
\text { after and } \\
\text { adopted } \\
\text { children }\end{array}$ & $\begin{array}{l}\text { Specialist service } \\
\text { for young people }\end{array}$ & $70-85 \%$ \\
\hline Vicky & $25-34$ & Last 2 years & $\begin{array}{l}\text { Adults / } \\
\text { older adults }\end{array}$ & $\begin{array}{l}\text { Neuropsychology } \\
\text { outpatient }\end{array}$ & $70-85 \%$ \\
\hline Monica & $25-34$ & $5-10$ years & Adults & $\begin{array}{l}\text { Adult Community } \\
\text { Mental Health } \\
\text { Team }\end{array}$ & $70-85 \%$ \\
\hline
\end{tabular}


Clinical psychologists use of reflective practice

Table 2. Representation of superordinate themes and subthemes.

\begin{tabular}{ll} 
Exploratory Questioning (7) & $\begin{array}{l}\text { Containment of own } \\
\text { Thoughts and Feelings in Human Survival (7) } \\
\text { Practice (5) }\end{array}$ \\
\hline
\end{tabular}

Gaining a different

perspective (7)

Managing the emotional impact of work (6)

New Insight (6)

Opening new possibilities (5)

Self-sustaining (5)

Leaving work at work (4)

Note: Brackets denote how many participants contributed to each theme and sub theme 